\title{
Effects of psychotherapy in moderately severe COPD: a pilot study
}

\author{
N. Eiser*, C. West*, S. Evans**, A. Jeffers**, F. Quirk+
}

Effects of psychotherapy in moderately severe COPD: a pilot study. N. Eiser, C. West, S. Evans, A. Jeffers, F. Quirk. CERS Journals Ltd 1997.

ABSTRACT: Anxiety is common in the "pink puffer" syndrome associated with chronic obstructive pulmonary disease (COPD). The degree of anxiety correlates well with perceived dyspnoea. This pilot study examines the effect of group psychotherapy on anxiety, exercise tolerance, dyspnoea and quality of life.

Ten patients with moderately severe, stable COPD (mean forced expiratory volume in one second $($ FEV1)=1.15 L) had six 90 min sessions of cognitive and behavioural psychotherapy at weekly intervals. Patients completed the Hospital Anxiety and Depression Scale (HADS), Medical Research Council Questionnaire (MRCQ) and St George's Respiratory Questionnaires (SGRQ), 1 week before and after therapy. FEV1, forced vital capacity (FVC), slow vital capacity (SVC), blood gas tensions and 6 min walking distance (6MWD) were measured. Eight control patients attended weekly for lung function and 6MWD for 6 weeks, but had no psychotherapy.

Mean baseline HADS score was significantly higher in the psychotherapy group (12) than in controls (7), but otherwise there were no differences in lung function, blood gas tensions, 6MWD, or the other questionnaire scores between groups. After treatment, the physiological and psychological parameters where unchanged in both groups with the exception of the mean 6MWD, which had improved in the psychotherapy group only, from 351 to $423 \mathrm{~m}(\mathrm{p}<0.001)$, an increase of $24 \%$. Three months after treatment, the 6MWD was still $16 \%$ above the baseline value $(p=0.02)$.

In conclusion, six sessions of cognitive and behavioural psychotherapy produced a sustained improvement in exercise tolerance in a group of 10 anxious patients with severe chronic obstructive pulmonary disease, without any change in anxiety scores on the Hospital Anxiety and Depression Scale. Further studies of more prolonged, intensive psychotherapy would establish whether better symptom and quality of life scores accompany more dramatic increases in exercise tolerance in "pink puffers". Eur Respir J 1997; 10: 1581-1584.

\author{
*Lewisham Hospital, London UK. **Division \\ of Psychiatry, Guy's Hospital, London UK. \\ +Division of Physiological Medicine, St \\ George's Hospital, London, UK. \\ Correspondence: N. Eiser \\ Lewisham Hospital \\ Lewisham High St \\ London SE13 6LH \\ UK \\ Keywords: Chronic obstructive pulmonary \\ disease
}

psychotherapy

Received: September 71995

Accepted after revision March 11997
In patients with chronic obstructive pulmonary disease (COPD), dyspnoea often correlates poorly with physiological impairment [1-3]. Anxiety is closely associated with dyspnoea, and may be one of the most important factors determining quality of life in patients with severe COPD [4, 5]. Attempts at improving dyspnoea, by means of psychotherapy, relaxation and retraining of breathing patterns, have met with varying success [6-9].

The aim of the present study was to assess the effect of general cognitive and behavioural psychotherapy, directed by a psychiatrist, on the level of anxiety, quality of life, dyspnoea and exercise tolerance in patients with moderately severe COPD.

\section{Methods}

\section{Patients}

Hospital Anxiety and Depression Scale (HADS) questionnaires were completed by patients attending the monthly COPD clinic at Lewisham Hospital over a 3 month period. The HADS [10] is a self-administered questionnaire, comprising 14 questions, seven of which are aimed to detect anxiety. Questions are based on psychic symptoms only, without reference to symptoms that could arise from a somatic cause. Each question is rated $0-3$, giving a possible score of 21 . Scores for anxiety only were calculated from the HADS questionnaires. ZigmOND and SNAITH [10] have shown a good correlation between the HADS score and severity of anxiety: $\leq 7$ denotes no anxiety; $8-10$ is borderline; and $\geq 11$ denotes clinical anxiety. From the responses received, 12 patients with severe but stable COPD and scores of $\geq 8$ for anxiety on HADS scoring agreed to enrol in the study. A further eight patients, matched for severity of dyspnoea and disability, agreed to act as controls. The male/female ratio was $4 / 8$ in the treatment group and $4 / 4$ in the control group. Mean age was 73 (range 60-80) yrs in the treatment group and 71 (range 59-77) yrs for controls. Mean \pm sD baseline forced expiratory volume in one second (FEV1) before bronchodilator was $46 \pm 17 \%$ of the predicted value for the treatment group and $34 \pm 13 \%$ pred for controls. No patient had had a chest infection within 1 month of the start of the study. For all patients, normal bronchodilators were omitted for $4 \mathrm{~h}$ before initial measurements on each day. 
All patients gave verbal informed consent and the study was approved by the Guy's and Lewisham Hospitals Ethics Committee.

\section{Measurements}

A dry spirometer (Vitalograph, Bucks, UK) was used to measure FEV1, forced vital capacity (FVC) and slow vital capacity (SVC). The best of three technically satisfactory measurements of each lung function test was recorded. Arterialized blood gas samples were obtained from the earlobe to measure arterial oxygen tension $\left(\mathrm{Pa}, \mathrm{O}_{2}\right)$ and arterial carbon dioxide tension $\left(\mathrm{Pa}, \mathrm{CO}_{2}\right)$. Six minute walking distance (6MWD) tests were carried out along indoor hospital corridors. The same investigator accompanied the patient on all occasions, leading the way and encouraging the patient to walk faster and to restart if they stopped. Patients were not allowed to talk while they walked or to sit down to rest. A score for dyspnoea was recorded on a $100 \mathrm{~mm}$ visual analogue scale (VAS) immediately after each walk: 0 was no breathlessness; and $100 \mathrm{~mm}$ was the most severe breathlessness imaginable. The scale was explained to the patient before and at the end of the test.

\section{Protocol}

Psychotherapy patients. There were six $90 \mathrm{~min}$ sessions at weekly intervals, each with a psychiatrist; patients were in groups of five or six. Patients were encouraged to discuss their physical symptoms as well as the psychological and physiological effects of their disease on the quality of their lives. They explored the concepts of anxiety, its links with breathlessness and ways of controlling anxiety. They were taught simple deep breathing exercises and deep muscle relaxation, as well as distraction techniques. In addition, they were given homework: breathing and relaxation exercises for $10 \mathrm{~min}$ three times daily with the aid of tapes. The groups were led by S.E. for the first three sessions and by A.J. for the final three sessions, due to the unavoidable absence of S.E.

One week before the trial, lung function and walks were completed before and $40 \mathrm{~min}$ after fenoterol, $400 \mu \mathrm{g}$, and oxitropium, $400 \mu \mathrm{g}$ had been inhaled from metereddose inhalers via a Volumatic device.

The following assessments were made on the first day (just before therapy), and at 1 week and 12 weeks after finishing the psychotherapy course: 1) patients completed the HADS, Medical Research Council Questionnaire (MRCQ) and St George's Respiratory Questionnaires (SGRQ) [11]; 2) 40 min after fenoterol, $400 \mu \mathrm{g}$, and oxitropium, $400 \mu \mathrm{g}$, had been inhaled, FEV1, FVC, SVC and 6MWD were measured.

Blood gas tensions were measured before and 1 week after completion of psychotherapy only.
Control patients. The patients attended the laboratory seven times, at weekly intervals. This was arranged in order to give them some reason to attend the Chest Clinic for the same number of times as the active treatment group. On each visit, FEV1, FVC, SVC, 6MWD and VAS dyspnoea scores were measured before and after fenoterol, $400 \mu \mathrm{g}$, and oxitropium, $400 \mu \mathrm{g}$, had been inhaled from metered-dose inhalers via a Volumatic. At Weeks 2 and 7, blood gas values were obtained and patients completed the HADS, MRCQ and SGRQ. The results from Weeks 2 and 7 were compared with those from the active treatment group on baseline and posttherapy days, using the postbronchodilator spirometry and walks.

\section{Statistical analysis}

Within-patient comparisons were made using paired t-tests for lung function, blood gas tensions, 6MWD and VAS scores for dyspnoea after exercise. In the active psychotherapy group, values at the start of the study were compared with those at 1 and 12 weeks after psychotherapy, and in the control patients the comparisons were made for values obtained after bronchodilators on Days 2 and 7.

Unpaired t-tests were used to compare indices between treatment and control groups. Wilcoxon rank scores compared results from the questionnaires.

\section{Results}

\section{Patient groups}

The demographic and baseline data for the two groups of patients are presented in table 1 . In the psychotherapy group, one patient declined to attend after one session,
Table 1. - Demographic details of patients participating in study

\begin{tabular}{|c|c|c|c|c|c|c|c|c|c|c|}
\hline $\begin{array}{l}\mathrm{Pt} \\
\text { No. }\end{array}$ & Sex & $\begin{array}{l}\text { Age } \\
\text { Yrs }\end{array}$ & $\begin{array}{c}\mathrm{FEV}_{1} * \\
\mathrm{~L}\end{array}$ & $\begin{array}{l}\text { FEV1* } \\
\% \text { pred }\end{array}$ & $\begin{array}{c}\mathrm{FVC}^{*} \\
\mathrm{~L}\end{array}$ & $\begin{array}{c}P_{\mathrm{a}, \mathrm{O}_{2}} * \\
\mathrm{kPa}\end{array}$ & $\begin{array}{c}P \mathrm{a}_{\mathrm{a}, \mathrm{CO}_{2}} \\
\mathrm{kPa}\end{array}$ & $\begin{array}{c}6 \mathrm{MWD} * \\
\mathrm{~m}\end{array}$ & $\begin{array}{c}\text { Anxiety } \\
\text { score }\end{array}$ & $\begin{array}{c}\text { Inhaled } \\
\text { drugs }\end{array}$ \\
\hline \multicolumn{11}{|c|}{ Treatment group } \\
\hline 1 & $\mathrm{~F}$ & 79 & 1.0 & 53 & 1.9 & 10.1 & 5.5 & 279 & 16 & $\mathrm{~S}$ \\
\hline 2 & $\mathrm{~F}$ & 79 & 1.5 & 78 & 2.1 & 7.0 & 4.3 & 150 & 15 & $\mathrm{~S}, \mathrm{~T}$ \\
\hline 3 & $\mathrm{~F}$ & 76 & 0.9 & 53 & 2.1 & 7.7 & 4.4 & 161 & 13 & S, I \\
\hline 4 & $\mathrm{M}$ & 80 & 0.6 & 32 & 2.2 & 8.2 & 5.7 & 204 & 8 & $\mathrm{~S}, \mathrm{I}$ \\
\hline 5 & $\mathrm{M}$ & 74 & 0.6 & 24 & 2.8 & 8.6 & 5.7 & 261 & 5 & S, I, B \\
\hline 6 & $\mathrm{~F}$ & 61 & 1.4 & 67 & 2.8 & 9.4 & 5.0 & 409 & 15 & $\mathrm{~S}, \mathrm{I}, \mathrm{B}, \mathrm{T}$ \\
\hline 7 & $\mathrm{~F}$ & 60 & 0.8 & 36 & 2.0 & 9.2 & 5.0 & 407 & 16 & $\mathrm{~S}, \mathrm{~T}$ \\
\hline 8 & $\mathrm{M}$ & 70 & 0.9 & 33 & 3.3 & 9.4 & 5.8 & 379 & 5 & $\mathrm{~S}$ \\
\hline 9 & $\mathrm{~F}$ & 68 & 0.9 & 47 & 2.3 & 7.9 & 5.9 & 266 & 15 & S, I \\
\hline 10 & M & 83 & 0.8 & 38 & 2.5 & 8.3 & 5.7 & 38 & 12 & S, I, B \\
\hline \multicolumn{11}{|c|}{ Control group } \\
\hline 11 & $\mathrm{~F}$ & 71 & 0.7 & 40 & 1.2 & 6.8 & 6.3 & 247 & 7 & S, I, B \\
\hline 12 & $\mathrm{M}$ & 77 & 0.5 & 20 & 2.1 & 7.8 & 5.3 & 259 & 5 & S, I, T \\
\hline 13 & M & 60 & 0.7 & 21 & 1.8 & 9.8 & 5.2 & 223 & 8 & S, I \\
\hline 14 & M & 79 & 1.1 & 41 & 2.6 & 9.7 & 4.6 & 493 & 7 & S \\
\hline 15 & M & 59 & 0.5 & 16 & 2.2 & 9.4 & 5.4 & 154 & 6 & S, I, B \\
\hline 16 & $\mathrm{~F}$ & 74 & 0.6 & 33 & 1.4 & 9.0 & 5.2 & 251 & 11 & S, I, B \\
\hline 17 & $\mathrm{~F}$ & 73 & 0.9 & 53 & 1.2 & 9.6 & 4.6 & 326 & 7 & $\mathrm{~S}, \mathrm{I}, \mathrm{B}, \mathrm{T}$ \\
\hline 18 & $\mathrm{~F}$ & 77 & 0.7 & 44 & 1.7 & 8.7 & 5.5 & 322 & 2 & $\mathrm{~S}, \mathrm{I}, \mathrm{T}$ \\
\hline
\end{tabular}

*: prebronchodilator baseline values; Pt: patient; F: female; M: male; FEV1: forced expiratory volume in one second; FVC: forced vital capacity; $\%$ pred: percentage of predicted value; $P \mathrm{a}_{1} \mathrm{O}_{2}$ : arterial oxygen tension; $P_{\mathrm{a}, \mathrm{CO}_{2}}$ : arterial carbon dioxide tension; 6MWD: 6 min walking distance; S: salbutamol; I: ipratropium; B: beclomethasone; T: theophylline. 
saying that it was a waste of time, and one patient was unable to attend for postpsychotherapy assessment due to a chest infection. Thus, the results of only 10 patients in the active treatment group were evaluable. All eight control patients had complete data for the study.

\section{Between-group comparisons}

Comparing treatment group with controls, there were no significant differences in lung function, blood gas tensions, 6MWD and VAS dyspnoea scores, either at the start of treatment or at the end of it (table 2). The scores from MRCQ and SGRQ were also comparable between groups. By contrast, the mean pretrial HADS score for anxiety was significantly higher in the treatment group $(12 \pm 4( \pm \mathrm{SD}))$ than in controls $(7 \pm 3 ; \mathrm{p}<0.01)$, as would be expected from the inclusion criteria.

\section{Effect of treatment}

In the control group, none of the physiological or psychological measures altered significantly during the study (table 2).

In the active treatment group, FEV1, SVC, blood gas tensions, VAS exertional dyspnoea score and psychological test scores were not significantly different at the end of psychotherapy compared to baseline values. However, FVC decreased slightly but significantly from 2.4 to $2.2 \mathrm{~L}(\mathrm{p}<0.05)$, and mean 6MWD increased very significantly from $351 \mathrm{~m}$ at baseline to $423 \mathrm{~m}$ after psychotherapy $(\mathrm{p}<0.001)$ : a mean improvement of $24 \%$.

Three months after psychotherapy, the mean 6MWD had fallen to $405 \mathrm{~m}$, but this was still $16 \%$ higher than pretrial levels. The difference at 3 months compared with baseline remained statistically significant $(\mathrm{p}<0.02)$, and there was no statistically significant difference in 6MWD at 1 week and 3 months postpsychotherapy.

Table 2. - Effects on lung function, blood gas tensions, walking distance and questionnaire scores

\begin{tabular}{|c|c|c|c|c|c|}
\hline & \multicolumn{3}{|c|}{ Treatment group } & \multicolumn{2}{|c|}{ Control group } \\
\hline & Baseline & $\begin{array}{l}\text { 1-week } \\
\text { post-Rx }\end{array}$ & $\begin{array}{l}3 \text { months } \\
\text { post-Rx }\end{array}$ & Baseline & 6 weeks \\
\hline $\mathrm{FEV}_{1} \mathrm{~L}$ & $1.2 \pm 0.3$ & $1.1 \pm 0.2$ & & $0.9 \pm 0.2$ & $0.9 \pm 0.2$ \\
\hline FVC L & $2.4 \pm 0.5$ & $2.2 \pm 0.4 *$ & & $2.4 \pm 0.7$ & $2.3 \pm 0.6$ \\
\hline SVC L & $2.6 \pm 06$ & $2.4 \pm 0.5$ & & $2.5 \pm 0.7$ & $2.3 \pm 0.5$ \\
\hline 6MWD m & $351 \pm 120$ & $423 \pm 134 * *$ & $405 \pm 166^{*}$ & $370 \pm 85$ & $378 \pm 70$ \\
\hline VAS score $\mathrm{mm}$ & $34 \pm 23$ & $36 \pm 24$ & $37 \pm 21$ & $55 \pm 27$ & $53 \pm 32$ \\
\hline $\mathrm{Pa}_{\mathrm{a}} \mathrm{O}_{2} \mathrm{kPa}$ & $8.6 \pm 0.9$ & $8.4 \pm 0.5$ & & $8.9 \pm 1.1$ & $8.6 \pm 0.9$ \\
\hline $\mathrm{Pa}_{\mathrm{a}, \mathrm{CO}_{2}} \mathrm{kPa}$ & $5.3 \pm 0.5$ & $5.3 \pm 0.4$ & & $5.3 \pm 0.6$ & $5.3 \pm 0.5$ \\
\hline HADS score & $12 \pm 4$ & $11 \pm 5$ & $10 \pm 1$ & $7 \pm 3^{++}$ & $7 \pm 3$ \\
\hline MRCQ score & $3 \pm 1$ & $3 \pm 2$ & $3 \pm 2$ & $3 \pm 1$ & $3 \pm 1$ \\
\hline \multicolumn{6}{|l|}{ SGRQ } \\
\hline Total score & $47 \pm 18$ & $49 \pm 19$ & $49 \pm 17$ & $64 \pm 15$ & $63 \pm 17$ \\
\hline Symptoms & $55 \pm 23$ & $57 \pm 24$ & $57 \pm 27$ & $72 \pm 11$ & $66 \pm 18$ \\
\hline Activities & $56 \pm 23$ & $60 \pm 25$ & $59 \pm 20$ & $75 \pm 11$ & $73 \pm 24$ \\
\hline Impacts & $39 \pm 22$ & $42 \pm 19$ & $39 \pm 20$ & $54 \pm 22$ & $55 \pm 15$ \\
\hline
\end{tabular}

Values are presented as mean \pm SD. Post-Rx: post-therapy; SVC: slow vital capacity; 6MWD: 6 min walking distance; VAS: visual analogue scale; HADS: Hospital Anxiety and Depression Scale; MRCQ: Medical Research Council Questionnaire; SGRQ: St George's Respiratory Questionnaire. For further definitions see legend to table $1 . *$ : $\mathrm{p}<0.05 ; * *$ : $\mathrm{p}<0.01$, compared to baseline (paired t-test). ${ }^{++}: \mathrm{p}<0.01$, compared to treatment group baseline (unpaired t-test).

\section{Discussion}

It is now widely accepted that pulmonary rehabilitation provides an important treatment option for patients with dyspnoea due to severe COPD $[12,13]$. Originally, the main components of rehabilitation were education, breathing training exercises, systemic exercises, pharmacological and oxygen treatment, and patient support groups [14]. More recently, the importance of psychological support as part of rehabilitation has increasingly been emphasized $[15,16]$.

There is little published information on the relative importance of psychological support, but ATKins et al. [17] found that a much longer rehabilitation programme than that used in the present study, including psychological sessions, was more effective in reducing anxiety than psychological sessions alone. In another large study, SASSi-Dambron et al. [18] found a significant improvement in the transitional dyspnoea index of MAHLER et al. [19] 6 months after treatment, in patients who had received six weekly sessions in which they were taught coping strategies by a psychotherapist, compared with patients who had general education sessions. Since no other changes were found and, in parno improvement in exercise tolerance, they attributed the difference to chance, because a large number of t-tests had been performed on the data. In that study, psychological support sessions were led by a psychotherapist, whereas in the present study they were led by a psychiatrist. The sessions in the study by SASSIDAMBRON et al. [18] concentrated particularly on education, muscle relaxation and breathing exercises, whereas in the present study the psychiatrist concentrated more on exploring the roots of the patients' anxieties and developing general psychological coping strategies. The breathing exercises were directed predominantly at general relaxation rather than training of muscle groups. No specific pulmonary rehabilitation measures were incorporated into the sessions.

In the present study, patients in both groups were demonstrably in a stable clinical state throughout the study; there being no change either in lung function or in blood gas tensions. As in previous studies [20,21], the 6MWD test proved a reliable and reproducible method for assessing exercise tolerance, since no significant changes in walking distances were seen comparing values at baseline and at the end of the study in the control group. Although the two groups were well matched in terms of lung function and walking distance, members of the treatment group were significantly more anxious than the control group. Whereas 7 out of 10 of the treatment group had scores of $\geq 12,6$ of the 8 control patients had anxiety scores within the normal range, albeit mostly at the top end of that range. This occurred by chance, the control patients being selected mainly for comparable disability in terms of breathlessness. In future studies, it would be advantageous to match patients for HADS scores to make the comparison more complete. It was 
surprising that the HADS anxiety scores did not improve after therapy, particularly since all patients who completed the course of treatment claimed to feel more relaxed and generally better. It is possible that the HADS score is not sensitive enough to have detected any changes achieved.

The only significant effect of the psychotherapy in the present study was the increase in exercise tolerance, which was partly sustained at 3 months after treatment. Since there was no comparable improvement in the control subjects, this was not due to a training effect from repeated walks nor to nonspecific encouragement from the staff during the repeated visits to the clinic. Nevertheless, the improvement in exercise tolerance, though highly statistically significant, was small in the active psychotherapy group and was not sufficient to produce any appreciable increase in activities or any significant enhancement in the quality of life. No relationship was found between initial HADS scores and any change either in HADS score or exercise tolerance following treatment. The unexpected necessity to change the psychiatrist leading the psychotherapy groups in mid-study may have reduced the potential effect of the treatment, due to differences in style and content of the sessions.

This was only a small pilot study, which produced interesting results in terms of improvement in exercise capacity after psychotherapy. Much larger numbers of patients would be required to establish whether this approach to treatment would be worthwhile routinely in the clinical setting for anxious patients with severe COPD. It is also possible that larger effects may be achieved in the future with a longer course of psychotherapy, and by ensuring treatment from the same therapist throughout the course of treatment.

In conclusion, in this pilot study, a 6 week course of cognitive and behavioural group psychotherapy from psychiatrists produced a sustained, modest improvement in exercise tolerance in anxious, breathless patients with moderately severe chronic obstructive pulmonary disease, without significantly alleviating their anxiety or improving their quality of life. A further larger study with a longer and/or more intensive course of psychotherapy may establish whether any improvement in quality of life is achievable, particularly in the anxious patient with chronic obstructive pulmonary disease. Such patients may be identified by a high anxiety score on Hospital Anxiety and Depression Scale testing.

\section{References}

1. Kinsman RA, Dahlem NW, Spector S, Staudenmayer $\mathrm{H}$. Observations on subjective symptomology, coping behaviour and medical decisions in asthma. Psychosom Med 1977; 39: 102-119.

2. Dahlem NW, Kinsman RA. Panic-fear in asthma: a divergence between subjective report and behavioural patterns. Percept Mot Skills 1978; 46: 95-98.
3. Fuhs MF. Correlates of dyspnea in individuals with chronic obstructive pulmonary disease. Doctoral dissertation. The Catholic University of America, 1980.

4. Dudley DL, Martin CJ, Holmes TH. Dyspnea: psychologic and physiologic observations. J Psychosom Res 1968; 11: 325-339.

5. Gift AG, Plaut M, Jacox A. Psychologic and physiologic factors related to dyspnea in patients with chronic obstructive pulmonary disease. Heart Lung 1986; 15 : 595-602.

6. Agle DP, Baum GL, Chester EH, Wendt M. Multidiscipline treatment of chronic pulmonary insufficiency. 1. Psychologic aspects of rehabilitation. Psychosom Med 1973; 35: 41-49.

7. Casciari RJ, Fairshter RD, Harrison A. Effects of breathing retraining in patients with chronic obstructive pulmonary disease. Chest 1981; 79: 393-398.

8. Rosser R, Denford J, Heslop A, et al. Breathlessness and psychiatric morbidity in chronic bronchitis and emphysema: a study of psychotherapeutic management. Psychol Med 1983; 13: 93-110.

9. Renfroe KL. Effect of progressive relaxation on dyspnea and state of anxiety in patients with chronic obstructive pulmonary disease. Heart Lung 1988; 17: 408-413.

10. Zigmond AS, Snaith RP. The Hospital Anxiety and Depression Scale. Acta Psychiatr Scand 1983; 67: 361-370.

11. Jones PW, Quirke FH. A self-complete measure of health status for chronic airflow limitation. Am Rev Respir Dis 1992; 145: 1321-1327.

12. Lertzman MM, Cherniak RM. Rehabilitation in patients with chronic obstructive pulmonary disease. Am Rev Respir Dis 1976; 114: 1145-1165.

13. Reis AL. Position paper of American Association of Cardiovascular and Pulmonary Rehabilitation. Scientific basis of pulmonary rehabilitation. J Cardiopulmon Rehab 1990; 10: 418-440.

14. Petty TL. Pulmonary rehabilitation in perspective: historical roots, present status and future projections. Thorax 1993; 48: 855-862.

15. Clarke CJ. Setting up a pulmonary rehabilitation programme. Thorax 1994; 49: 270-278.

16. Celli BR. Pulmonary rehabilitation in patients with COPD. Am J Respir Crit Care Med 1995; 152: 861-864.

17. Atkins BJ, Kaplan RM, Timms RM, Reinsch S, Zofback $\mathrm{K}$. Behavioral exercise programs in the management of chronic obstructive pulmonary disease. J Consult Clin Psychol 1984; 52: 591-603.

18. Sassi-Dambron DE, Eakin EG, Ries AL, Kaplan RM. Treatment of dyspnea in COPD: a controlled clinical trial of dyspnea management strategies. Chest 1995; 107: 724-729.

19. Mahler DA, Weinberg DH, Wells CK, et al. The measurement of dyspnea: contents, interobserver agreement and physiologic correlates of two new clinical indexes. Chest 1984; 85: 751-758.

20. Mungall IPF, Hainsworth R. Assessment of respiratory function in patients with chronic obstructive airways disease. Thorax 1979; 34: 254-258.

21. Eiser N, Denman WT, West C, Luce P. Oral diamorphine: lack of effect on dyspnoea and exercise tolerance in the "pink puffer" syndrome. Eur Respir J 1991; 4: 926-931. 